\title{
Liver mitochondrial dysfunction is reverted by insulin-like growth factor II (IGF-II) in aging rats
}

\author{
Maria Garcia-Fernandez ${ }^{1}$ Inma Sierra², Juan E Puche ${ }^{2}$, Lucia Guerra ${ }^{2}$ and Inma Castilla-Cortazar ${ }^{2 *}$
}

\begin{abstract}
Background: Serum IGF-I and IGF-II levels decline with age. IGF-I replacement therapy reduces the impact of age in rats. We have recently reported that IGF-II is able to act, in part, as an analogous of IGF-I in aging rats reducing oxidative damage in brain and liver associated with a normalization of antioxidant enzyme activities. Since mitochondria seem to be the most important cellular target of IGF-I, the aim of this work was to investigate whether the cytoprotective actions of IGF-II therapy are mediated by mitochondrial protection.

Methods: Three groups of rats were included in the experimental protocol young controls (17 weeks old); untreated old rats (103 weeks old); and aging rats (103 weeks old) treated with IGF-II (2 $\mu \mathrm{g} / 100 \mathrm{~g}$ body weight and day) for 30 days.

Results: Compared with young controls, untreated old rats showed an increase of oxidative damage in isolated mitochondria with a dysfunction characterized by: reduction of mitochondrial membrane potential (MMP) and ATP synthesis and increase of intramitochondrial free radicals production and proton leak rates. In addition, in untreated old rats mitochondrial respiration was not blocked by atractyloside. In accordance, old rats showed an overexpression of the active fragment of caspases 3 and 9 in liver homogenates. IGF-II therapy corrected all of these parameters of mitochondrial dysfunction and reduced activation of caspases.
\end{abstract}

Conclusions: The cytoprotective effects of IGF-II are related to mitochondrial protection leading to increased ATP production reducing free radical generation, oxidative damage and apoptosis.

\section{Background}

The reduced activity of the GH-IGFs axis leads to a condition known as the somatopause [1], which is characterised by a decrease in lean body mass and an increase in adipose mass, osteopenia, muscle atrophy, reduced exercise tolerance and changes in the plasma lipoprotein profile [2]. These alterations are similar to those observed in younger adults with GH deficiency [3]. Understanding that aging is an unrecognized condition of "IGF-I deficiency", we have recently reported that IGF-I replacement therapy restores many agerelated changes increasing testosterone levels and serum total antioxidant capability and reducing oxidative damage in brain and liver [4]. This cytoprotective (neuroprotective and hepatoprotective) activity of IGF-I in

\footnotetext{
* Correspondence: iccortazar@ceu.es

${ }^{2}$ Department of Medical Physiology, CEU-San Pablo University School of Medicine Institute of Applied Molecular Medicine (IMMA) Boadilla del Monte, 28668 Madrid, Spain

Full list of author information is available at the end of the article
}

aging rats is related to mechanisms of mitochondrial protection including normalization of the potential membrane and ATP synthesis and reduction of intramitochondrial free radicals production [5].

More recently we have reported that IGF-II is able to act, in part, as an analogous of IGF-I in aging rats inducing neuroprotection and hepatoprotection without increasing testosterone levels [6].

Mitochondria are specially sensitive to oxidative damage in the pathogenesis of disease and aging $[7,8]$. Normal mitochondrial function is a critical place in maintaining cellular homeostasis because mitochondria produce ATP and they are the major intracellular source of free radicals. Intracellular or extracellular insults converge on mitochondria [9] and induce a sudden increase in permeability of the inner mitochondrial membrane the so-called mitochondrial membrane permeability transition (MMPT). The MMPT is caused by the pores opening in the inner mitochondrial membrane, dissipation of proton gradient, matrix swelling and outer

\section{Ciomed Central}


membrane rupture [8-12]. The MMPT is an endpoint to initiate cell death because the pore opening lead to the release of the mitochondrial cytochrome $\mathrm{c}$ activating the apoptotic pathway of caspases.

One of the most sensitive points for the pore opening is the adenosine nucleotide translocator (ANT) [10]. Since mitochondria are one of the most important cellular targets of IGF-I, the aim of this work was to investigate if the cytoprotective properties of IGF-II therapy are also related to mitochondrial protection.

Recently we have characterized the mitochondrial dysfunction in aging rats in a similar protocol [5]. In the present work, the following parameters were studied: mitochondrial membrane potential, intramitochondrial Reactive Oxygen Species (ROS) production, ATP synthesis, oxygen consumption, proton leak rates, vulnerability of pore opening and caspases activation [10-16] in young controls, untreated old rats and old rats treated with IGF-II, at low doses, for 30 days.

\section{Materials and methods}

\section{Animals and experimental design}

All experimental procedures were performed in compliance with The Guiding Principles for Research Involving Animals [17]. Healthy male Wistar rats, 17 weeks old (wk), were used in this protocol as young controls (group yCO, $\mathrm{n}=6$ ), and healthy male Wistar rats of 103 wk old were randomly assigned to receive either saline (0.5 mL, group $\mathrm{O}, \mathrm{n}=6$ ) or recombinant human IGF-II (Lilly Laboratories, Madrid, Spain) subcutaneously (2 $\mu \mathrm{g}$ IGF-II/100 g body weight and day in $0.5 \mathrm{~mL}$ of saline in two divided doses, group O+IGF-II, $\mathrm{n}=6$ ) for 30 days.

Both food (standard semipurified diet for rodents; B.K. Universal, Sant Vicent del Horts, Spain) and water were given ad libitum. Rats were housed in cages placed in a room with a 12-h light, 12-h dark cycle, and constant humidity and temperature $\left(20^{\circ} \mathrm{C}\right)$.

In the morning of the 31 st day, rats were killed by decapitation, and the liver was dissected. Fresh liver was used to isolate mitochondria and to perform mitochondrial function tests using flow cytometry $[4,11]$.

Samples were obtained simultaneously from young, old-untreated rats, and old rats treated with IGF-II to have paired data.

\section{Isolation of liver mitochondria}

Liver mitochondrial fraction was prepared according to the method described by Schneider and Hogeboom with modifications [12]. Liver samples were homogenized (1:10 wt/vol) in an ice-cold isolation buffer containing sucrose $0.25 \mathrm{M}$ and $0.1 \%$ BSA buffered ( $\mathrm{pH} 7.4$ ) with Tris- $\mathrm{HCl} 10 \mathrm{mM}$, and the isolation medium was identical without BSA or EDTA. The protein concentration was measured using the Biuret method. The homogenate was centrifuged at $800 \times g$ for $10 \mathrm{~min}$. The resulting supernatant was centrifuged at $8,500 \times g$ for $10 \mathrm{~min}$. The supernatant was discarded, and the pellet was diluted in cold isolation buffer and centrifuged at $8,500 \times g$ for $10 \mathrm{~min}$ three times. The final mitochondria pellet was resuspended in a minimal volume, and aliquots were stored at $-80^{\circ} \mathrm{C}$ until use in enzyme assays. All procedures were conducted at $4^{\circ} \mathrm{C}$.

Unless otherwise indicated, the standard incubation medium had the following composition: $100 \mathrm{mM} \mathrm{NaCl}$, $5 \mathrm{mM}$ sodium-potassium phosphate buffer ( $\mathrm{pH} 7.4), 10$ $\mathrm{mM}$ Tris- $\mathrm{HCl}$ buffer ( $\mathrm{pH} 7.4$ ), and $10 \mathrm{mM} \mathrm{MgCl}_{2}$.

The respiratory substrates used were $5 \mathrm{mM}$ potassium glutamate plus $2.5 \mathrm{mM}$ potassium malate and $5.0 \mathrm{mM}$ potassium succinate plus $4 \mu \mathrm{M}$ rotenone.

\section{Oxygen consumption}

Oxygen consumption was measured using a Clark-type electrode (Hansatech Instruments Ltd., using software OXIGRAPH version 1.10; Norfolk, UK) in a $2 \mathrm{~mL}$ glass chamber equipped with magnetic stirring.

The reaction was started by the addition of $6 \mathrm{mg}$ mitochondrial protein to $2 \mathrm{~mL}$ standard medium containing rotenone $5 \mu \mathrm{M}$, oligomycin $1.3 \mathrm{mM}$, nigericin $100 \mathrm{pmol} / \mathrm{mg}$ protein, succinate $10 \mathrm{mM}$, ADP $200 \mu \mathrm{M}$, and glutamate/malate $5 / 2.5 \mathrm{mM}$. Finally, it was stabilized for $1 \mathrm{~min}$ at $30^{\circ} \mathrm{C}$. Respiration rates are given in nAtom-gram oxygen/mg.min. Phosphorylating respiration (state 3) was initiated by addition of $200 \mathrm{nmol}$ $\mathrm{ADP} / \mathrm{mg}$ protein. Phosphorylation efficiency (ADP/O ratio) was calculated from the added amount of ADP and total amount of oxygen consumed during state 3 . The state 4 is obtained with all substrates but ADP.

The ratio between state 3 rate and state 4 rate is called the respiratory control ratio (RCR), and indicates the tightness of the coupling between respiration and phosphorylation. With isolated mitochondria the coupling is not perfect, probably as a result of mechanical damage during the isolation procedure. Typical RCR values range from 3 to 10, varying with the substrate and the quality of the preparation. Coupling is thought to be better in vivo but may still not achieve $100 \%$.

\section{Flow cytometry analysis}

Gated mitochondrial population was chosen by flow cytometry, based on forward scatter and side scatter within mitochondria samples, after obtaining one clear mitochondria population.

\section{Mitochondrial transmembrane electrical potential (MMP)}

MMP $(\Delta \Psi)$ was measured by the lipophilic cationic fluorescent probe Rh-123 (Molecular Probes Inc., Eugene, OR), a fluorescent derivative of uncharged dihydroRh-123, according to previous studies $[4,5,12]$. A mitochondrial suspension $(50 \mu \mathrm{g} / \mathrm{mL})$ was incubated 
with the same respiratory substrates used in oxygen uptake for $1 \mathrm{~min}$ at room temperature, and after adding Rh-123 (260 $\mathrm{nM}$ ) and incubating it for another minute. After incubation, suspensions were immediately analyzed by flow cytometry. The values of the fluorescence (FL) substrates were normalized to the value obtained with the uncoupler carbonylcyamide-mchlorophenylhydrazone.

\section{Rate of intramitochondrial reactive oxygen species (ROS) generation}

The rate of ROS generation from mitochondria was measured after the formation of Rh-123 using the cytometry method performed by O'Connor [12] with a small modification. A mitochondrial suspension $(100 \mu \mathrm{g} / \mathrm{mL})$ was incubated with $0.82 \mathrm{nM}$ dihydro Rh-123 and $7 \mathrm{U} /$ $\mathrm{mL}$ horseradish peroxidase for $5 \mathrm{~min}$ at room temperature. The values of the FL substrates were normalized to the value obtained without peroxidase and adding the uncoupler CCCP. $\mathrm{H}_{2} \mathrm{O}_{2}(1 \mathrm{mM})$ was used with the positive control.

After incubation, the suspensions were immediately analyzed. Gated mitochondrial population was chosen by flow cytometry, based on forward scatter and side scatter within mitochondria samples.

Cytofluorometric analysis was performed using a flow cytometer EPICS XL (Beckman Coulter, Inc., Fullerton, CA) equipped with a single $488 \mathrm{~nm}$ argon laser (15 $\mathrm{mW})$. Green FL was detected with a wide-band filter for Rh-123 centred in $525 \pm 20 \mathrm{~nm}$ (FL1). A standard cytogram based on the measurement of right angle scatter vs. forward angle scatter was defined to eliminate cellular debris and aggregates. A minimum of 10,000 mitochondria per sample was acquired in list mode and analyzed with System II version 3.0 Software (Beckman Coulter).

\section{Activities of mitochondrial complexes}

Mitochondrial suspensions were thawed and diluted with potassium phosphate. Activities of the respiratory chain enzymes were measured at $37^{\circ} \mathrm{C}$ in Cobas Mira (ABXMicro, Mannheim, Germany).

\section{Measurements of cytochrome oxidase activity}

Cytochrome oxidase activity was measured according to the method described by Cortese et al. [16]. Mitochondria were resuspended in the medium containing (in mM) 220 mannitol, 70 sucrose, $2.5 \mathrm{~K}_{2} \mathrm{HPO}_{4}, 2.5 \mathrm{MgCl}_{2}$, and 0.5 EDTA. Antimycin A was then added to block mitochondrial respiration through complex III. Reaction was started by adding ascorbate $/ N, N, N^{\prime}, N^{\prime}$-tetramethyl$p$-phenylenediamine as an electron donor.

\section{Complex V, ATPase (EC 3.6.1.34.)}

The activity was assayed by coupling the reaction to the pyruvate kinase and lactate dehydrogenase systems, and measuring reduced nicotinamide adenine dinucleotide
(NADH) oxidation at $340 \mathrm{~nm}$. The assay system contained Tris- $\mathrm{HCl}$ buffer $65 \mathrm{mM}$ (pH 7.5), sucrose 300 $\mathrm{mM}, \mathrm{MgCl} 24.75 \mathrm{mM}$, ATP $4 \mathrm{mM}$, NADH $0.4 \mathrm{mM}$, phosphoenolpyruvate $0.6 \mathrm{mM}$, potassium cyanide 5 $\mathrm{mM}$, pyruvate kinase $700 \mathrm{U} / \mathrm{mL}$, and lactate dehydrogenase $1000 \mathrm{U} / \mathrm{mL}$.

\section{Assessment of "proton leak": the relationship between respiration rate and MMP $(\Delta \Psi)$}

Mitochondrial proton leak was calculated from respiration rates and MMP expressing the ratio of protons for each oxygen atom consumed [13-15]. The rate of proton leak across the inner mitochondrial membrane is a function of the driving force (membrane potential) and increases disproportionately with membrane potential.

Titration of membrane potential and state 4 oxygen consumption by respiratory inhibitors were performed simultaneously in separate vessels at $30^{\circ} \mathrm{C}$. Nigericin was added to collapse the $\mathrm{pH}$ difference across the mitochondrial inner membrane and, thus, $\Delta \Psi$ had the value of the proton motive force $(\Delta \mathrm{p})$. Reactions were started by the addition of $3 \mathrm{mg}$ mitochondrial protein/mL standard medium containing also $3 \mathrm{mM}$ rotenone, $1.3 \mathrm{mM}$ oligomycin, nigericin (100 pmol/mg protein), and $5 \mathrm{mM}$ succinate. The addition of inhibitors was begun when the maximum value of the potential became stable (after $\sim 2-3 \mathrm{~min}$ ). When succinate was used as the substrate, the titration was performed with malonate (K/salt) from 0-13 $\mathrm{mM}$; at the end of each membrane potential trace, the zero point was determined by addition of CCCP 1 $\mathrm{mM}$. Rates of respiration during the titration with inhibitors were measured with a Clark-type oxygen electrode, and membrane potential with a flow cytometer simultaneously with the measurements of membrane potential.

\section{Inhibition of Adenine Nucleotide Translocase (ANT) by Atractyloside (Atr)}

To establish the optimal concentration of Atr (Calbiochem-Novabiochem, San Diego, CA) needed for ANT inhibition, the efficiency of Atr was first examined in its classical role, i.e. for its ability to inhibit oxidative phosphorylation. For analysis, increasing Atr concentrations (50-200 $\mathrm{pmol} / \mathrm{mg}$ mitochondrial protein) were used until complete inhibition of oxygen consumption was obtained $[9,18,19]$.

\section{Oxidative damage and total antioxidant status (TAS) in isolated mitochondria}

Lipid hydroperoxides (LOOHs) were assessed in isolated mitochondria as previously described by Arab and Steghens [20], and adapted for Cobas Mira (600 nm wavelength) and mitochondria suspensions. Briefly, orange xylenol $(180 \mu \mathrm{L}-167 \mu \mathrm{M})$ was added to $25 \mu \mathrm{L}$ sample. 
The first optic reading was obtained before the addition of iron gluconate $(45 \mu \mathrm{L}-833 \mu \mathrm{M})$. LOOH was calculated using a standard curve of tert-butyl hydroperoxide, and $\mathrm{LOOH}$ levels were expressed as $\mathrm{nmol} / \mathrm{mg}$ mitochondrial protein. Intraassay and interassay coefficients were 3 and $8 \%$, respectively.

TAS, as total enzymatic and nonenzymatic antioxidant capability, was evaluated in isolated mitochondria by a colorimetric assay (Randox Laboratories Ltd., Ardmore, Crumlin, UK) using the following principle: 2,2'-azino-di('3-ethylbenzthiazoline sulfonate) was incubated with a peroxidase (metmyoglobin) and $\mathrm{H}_{2} \mathrm{O}_{2}$ to produce the radical cation 2,2'-azino-di-('3-ethylbenzthiazoline sulfonate $)^{-+}$. This has a relatively stable blue-green colour, which is measured at $600 \mathrm{~nm}$. Antioxidants in the added sample cause suppression of this colour production to a degree that is proportional to their concentration $[21,22]$.

\section{Assay for Caspase-3 and 9-Associated Activity}

The cytoplasm and nuclear fractions were obtained by cell fractionation. Briefly, tissue was disrupted and treated with lysis buffer $(800 \mu \mathrm{L})$ containing $10 \mathrm{mM}$ HEPES, $\mathrm{pH}$ 7.9, $10 \mathrm{mM} \mathrm{KCl}, 0.1 \mathrm{mM}$ ethylenediaminetetraacetic acid (EDTA), $0.1 \mathrm{mM}$ EGTA, $5 \mu \mathrm{g} / \mathrm{mL}$ aprotinin, $10 \mu \mathrm{g} /$ $\mathrm{mL}$ leupeptin, $0.5 \mathrm{mM}$ phenylmethylsulfonyl fluoride, 1 $\mathrm{mM}$ ditiothreitol (DTT), and 0.6\% Nonidet NP-40 for $10 \mathrm{~min}$ on ice. Afterward, samples were homogenized and centrifuged at $15,000 \mathrm{~g}$ for $3 \mathrm{~min}$ at $4{ }^{\circ} \mathrm{C}$. Aliquots of the supernatant (cytoplasm) were stored at $-80{ }^{\circ} \mathrm{C}$ until use for the measurement caspase- 3 activation. The pellet (nuclear fraction) was discarded. The caspase-3associated activity in the sample $(25 \mu \mathrm{g})$ was measured using N-acetyl-Asp-Glu-Val-Asp-7-amino-4-trifluoromethy coumarin (Ac-DEVD-AFC, Bachem AG, Bubendorf, Switzerland) $(100 \mu \mathrm{M})$ in caspase-incubating buffer (50 mM HEPES pH 7.5, $100 \mathrm{mM} \mathrm{NaCl}, 10 \%$ sucrose, $0.1 \%$ CHAPS, $1 \mathrm{mM}$ EDTA, and $5 \mathrm{mM}$ DTT) up to 100 $\mu \mathrm{L}$ of total volume. The fluorescence of the sample (Ex $=400$, and $\mathrm{Em}=505)$ was recorded using a GENios Microplate Reader (TECAN, Salzburg, Austria).

\section{Statistical analysis}

Data are expressed as means \pm sem. Statistical significance was estimated with the paired or unpaired $t$ test as appropriate. A $P$ value lower than 0.05 was considered significant (*p $<0.05$ vs yCO and ${ }^{*} \mathrm{p}<0.05$ vs $\mathrm{O}$ ). All analyses were performed using the SPSS version 15.0 (SPSS, Inc., Chicago, IL) statistical package.

\section{Results}

The mitochondrial dysfunction in aging rats was previously characterized [5] in isolated hepatic mitochondria.

\section{Effect of low doses of IGF-II on Mitochondrial Membrane Potential (MMP)}

The MMP, which is considered a good marker of mitochondrial function, was monitored by FL quenching of $\mathrm{Rh}-123$ in mitochondria from the livers of rats under different conditions: the resting state 4 (with all substrates but ADP); the active state 3 (with ADP); and with oligomycin, which deactivates ATPase showing the conditions of maximum intramitochondrial negativity.

Table 1 summarizes the MMP values, expressed as arbitrary units (AU), in the three experimental groups, when succinate was used as substrate. According to previous data [5], a reduction of MMP was observed in untreated aging rats compared with young controls, which IGF-II therapy was able to restore to similar values to those found in young controls, as IGF-I replacement therapy had reached $[4,5]$. No changes were observed using glutamate/malate as substrates (see Additional File 1, Table S1).

\section{Mitochondrial oxygen consumption}

Table 2 shows oxygen consumption under different conditions and Respiratory Control Ratios (RCRs) in mitochondria from the three experimental groups, when succinate was used as substrate. Untreated old rats $(\mathrm{O}$ group) showed higher values of oxygen consumption compared with young controls, but no significant differences were found between yCO and O+IGF-II groups. Interestingly, mitochondria from old rats treated with IGF-II expended significantly lower amounts of oxygen compared with untreated old animals $(P<0.05)$ with a significantly better efficiency because MMP returned to values similar to those found in young controls, whereas $\mathrm{O}$ group showed a depletion of MMP as is described in Table 1 and in a preliminary study [6]. However, when glutamate/malate were used as substrates, no significant changes were found (Suppl. Table 1).

In addition, the ratio ADP/Oxygen (ADP/O) expressing oxidative phosphorylation as ATP produced by oxygen molecule consumed, was significantly reduced in mitochondria from $\mathrm{O}$ group $(\mathrm{P}<0.05 v s$. yCO and $\mathrm{O}$ + IGF-II groups), when either succinate (Table 2) or glutamate/malate (Suppl. Table 1) were used as substrates, whereas old rats treated with low doses of IGF-II showed similar values to those found in young controls.

No significant differences were found among the three experimental groups in RCRs (state 3 to state 4 ).

\section{Proton leak rates}

The rate of proton leak across the inner mitochondrial membrane is a function of the driving force (membrane potential) and increases disproportionately with membrane potential $[13,14]$. Proton leak rates express "proton escape" into mitochondrial matrix contributing to dissipation of the MMP in pathological conditions. 
Table 1 Mitochondrial Membrane Potential (expressed as arbitrary units of fluorescence, AUF) in isolated liver mitochondria from the three experimental groups, using succinate as substrate.

\begin{tabular}{cccc}
\hline & Young controls $(\mathbf{y C O})(\mathbf{n}=\mathbf{6})$ & $\begin{array}{c}\text { Untreated old rats }(\mathbf{O}) \\
(\mathbf{n}=\mathbf{6})\end{array}$ & Old rats treated with IGF-II O+IGF-II (n= 6) \\
\hline Succinate (State 4) & $191.90 \pm 18.05$ & $160.55 \pm 16.15^{\mathrm{a}}$ & $188.60 \pm 19.00^{\mathrm{b}}$ \\
+ ADP (State 3) & $133.95 \pm 13.30$ & $125.40 \pm 17.10$ & $131.40 \pm 11.40$ \\
+ Oligomycin & $217.55 \pm 17.10$ & $158.65 \pm 17.10^{\mathrm{a}}$ & $223.85 \pm 14.25^{\mathrm{b}}$ \\
\hline
\end{tabular}

Values are mean \pm SEM. $P$, ns yCO group vs. O+IGF-II group in all conditions.

a $P<0.05$ vs yCO

${ }^{b} P<0.05$ vs $O$

Figure 1 shows the proton leak curves in the three experimental groups, expressed by oxygen consumption $\left(\mathrm{nAgO} \cdot \mathrm{mg}^{-1} \cdot \mathrm{min}^{-1}\right.$ ) at a given MMP in state 4 (without ADP). Mitochondria from untreated old rats needed to consume more oxygen to reach the same MMP values as compared to young controls. As Figure 1 express in mitochondria from old animals treated with IGF-II the "proton escape" was reduced suggesting a more effective utilization of the oxygen leading to a suitable proton gradient.

Intramitochondrial Reactive Oxygen Species (ROS) production

Figure 2 shows the intramitochondrial ROS production in isolated mitochondria from the three experimental groups. Mitochondria from untreated aging rats showed a significant increase of ROS generation compared with mitochondria from young controls and O+IGF-II.

All these data prove an incorrect use of oxygen by mitochondria from untreated old rats, which do not achieve the suitable proton gradient. Consequently the MMP results insufficient for the activity of the ATP synthase.

\section{Activities of cytochrome oxidase and ATP synthase} complexes

Cytochrome oxidase activity $\left(\mathrm{nAgO} \cdot \mathrm{mg}^{-1} \cdot \mathrm{min}^{-1}\right.$ ) expressed as oxygen consumption in this complex was significantly reduced in $\mathrm{O}$ group compared with young controls (yCO: $65.45 \pm 3.90$ vs. O: $46.10 \pm 5.75 ; P$ $<0.05)$. However, no differences were found between
yCO group and old rats treated with IGF-II $(\mathrm{O}+\mathrm{IGF}-\mathrm{II}$ : $61.48 \pm 7.10, P=$ not significant $v s$. $\mathrm{yCO}$ and $P<0.05$ vs. O group).

ATPase activity (expressed as $\mu$ mol ATP produced per molecule of Oxygen consumed) was significantly reduced in untreated aging rats $(\mathrm{O}: 0.13 \pm 0.01$ vs $\mathrm{yCO}$ : $0.18 \pm 0.01, P<0.05)$. However, there were no significant differences between yCO and O+IGF-II groups in complex $\mathrm{V}$ activity $(\mathrm{O}+\mathrm{IGF}-\mathrm{II}: 0.20 \pm 0.02, P<0.05$ vs O group), according to preliminary data [6].

\section{Estimation of the vulnerability to pore opening by Atractyloside (Atr) \\ Blockage of oxygen consumption by Atr}

In physiological conditions Atr competes with ADP in ANT blocking mitochondrial respiration. Full inhibition of the oxygen consumption induced by addition of ADP was obtained in liver mitochondria from young controls at a concentration of $150 \mathrm{pmol} / \mathrm{mg}$ Atr: see Figure 3.

In this environment of increased intracellular ROS in old rats, ANT can be oxidized [18,19], leading to an eventually uncoupling of this transporter. In this condition, mitochondrial respiration becomes Atr insensitive. Consistently with this hypothesis, our study show that Atr did not inhibit respiration in mitochondria from untreated aging rats (O group) (Figure 3). Interestingly, Atr inhibition was close to young controls in mitochondria from $\mathrm{O}+\mathrm{IGF}-\mathrm{II}$ showing a normal ANT coupling. In this group $(\mathrm{O}+\mathrm{IGF}-\mathrm{II})$ as shown in Figure 3, full

Table 2 Oxygen consumption by mitochondria from the three experimental groups, using succinate as substrate.

\begin{tabular}{lccc}
\hline & Young controls $(\mathbf{y C O})(\mathbf{n}=\mathbf{6})$ & Untreated old rats $(\mathbf{O})(\mathbf{n}=\mathbf{6})$ & Old rats treated with IGF-II O+IGF-II $(\mathbf{n}=\mathbf{6})$ \\
\hline $\begin{array}{l}\text { State } 4 \\
\left(\mathrm{nAgO} \cdot \mathrm{mg}^{-1} \cdot \mathrm{min}^{-1}\right)\end{array}$ & $27.55 \pm 2.85$ & $19.95 \pm 1.90$ & $23.00 \pm 2.00$ \\
State 3 & $88.35 \pm 6.65$ & $62.70 \pm 5.70^{\mathrm{a}}$ & $74.00 \pm 15.00$ \\
$\left(\mathrm{nAgO} \cdot \mathrm{mg}^{-1} \cdot \mathrm{min}^{-1}\right)$ & $3.30 \pm 0.80$ & $3.10 \pm 0.50$ & $3.20 \pm 0.90$ \\
RCR & $1.71 \pm 0.19$ & $1.05 \pm 0.28^{\mathrm{a}}$ & $2.01 \pm 0.41^{\mathrm{b}}$ \\
ADP/Oxygen & &
\end{tabular}

Values are mean \pm SEM. ADP/Oxygen expresses oxidative phosphorylation: ATP produced by oxygen molecule consumed. RCR $=$ Respiratory Control Ratio (ratio State $3 /$ State 4$)$.

${ }^{a} P<0.05$ vs. yCO group

${ }^{b} P<0.05$ vs. O group 


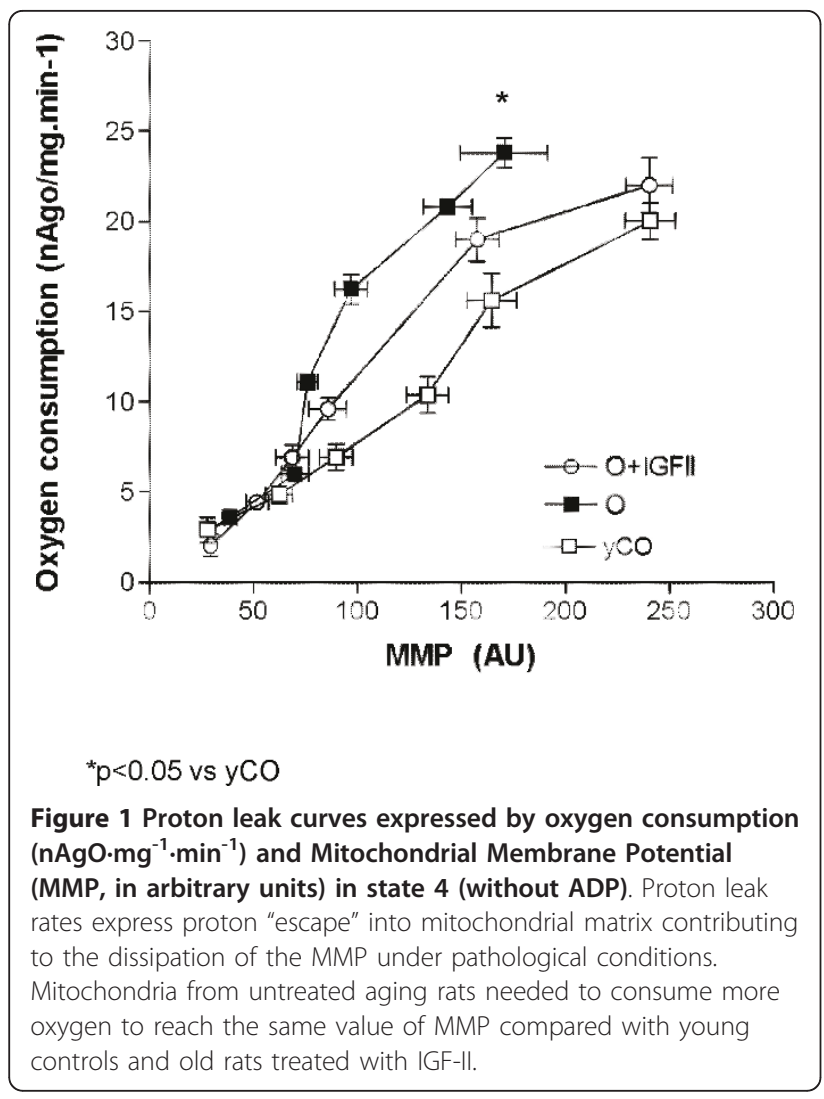

inhibition of the oxygen consumption was obtained at a concentration of $200 \mathrm{pmol} / \mathrm{mg}$ Atr.

\section{Mitochondrial oxidative damage and Total Antioxidant Status (TAS) in isolated liver mitochondria}

Figure 4 shows intramitochondrial oxidative damage, using lipid hydroperoxides (LOOHs) as markers [20-22], and total antioxidant capability of isolated mitochondria $[21,22]$. Mitochondria from untreated old rats showed an increase in oxidative damage and a reduction in TAS

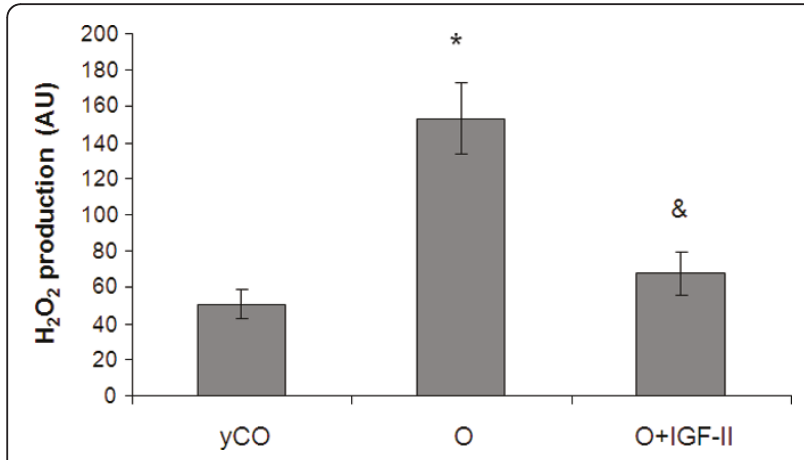

Figure 2 Intramitochondrial $\mathrm{H}_{2} \mathrm{O}_{2}$ production in isolated mitochondria from the three experimental groups.

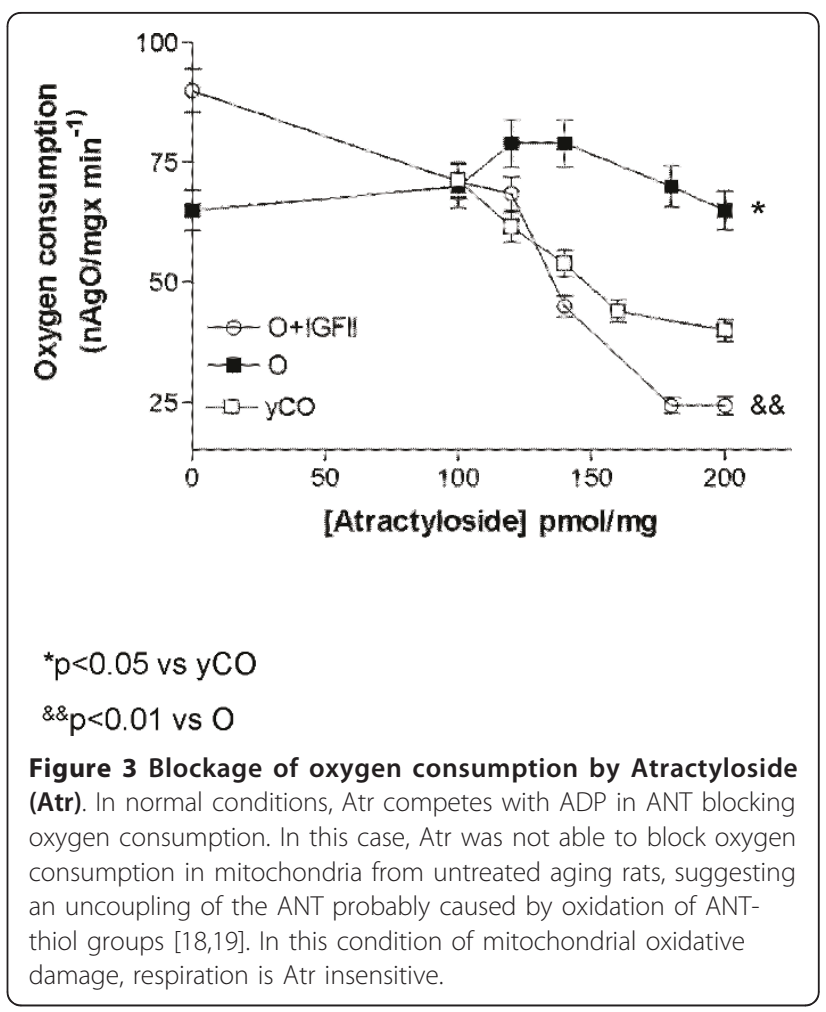

compared with young controls. IGF-II therapy was able to improve both parameters.

\section{Effect of IGF-II on caspase 3 and caspase 9 activity}

Assays for caspase 3 associated activity showed a significant increase of caspase 3 activation in untreated aging rats compared with young controls (Figure 5). However, a reduction in the expression of the active fragment of caspase 3 was observed in old animals treated with IGF-II.

Caspase 9 showed the same pattern with an increased activity in untreated aging rats compared with young controls (Figure 5; $P<0.05$ ). Again, IGF-II treatment induced a significant reduction of the activity of caspase 9 proving a diminution of this apoptotic pathway.

\section{Discussion}

The impact of the reduced activity of GH/IGFs axis in age-related changes is not fully understood. It has been demonstrated that IGF-I replacement therapy reduces the impact of age in rats [4,5], improving glucose and lipid metabolisms, increasing testosterone levels and serum total antioxidant capability and reducing oxidative damage in brain and liver associated with a normalization of antioxidant enzyme activities and mitochondrial function.

These beneficial effects of IGF-I may have been due to suppressing endogenous $\mathrm{GH}$ release. Current studies in our laboratory are designed to prove this mechanism. 

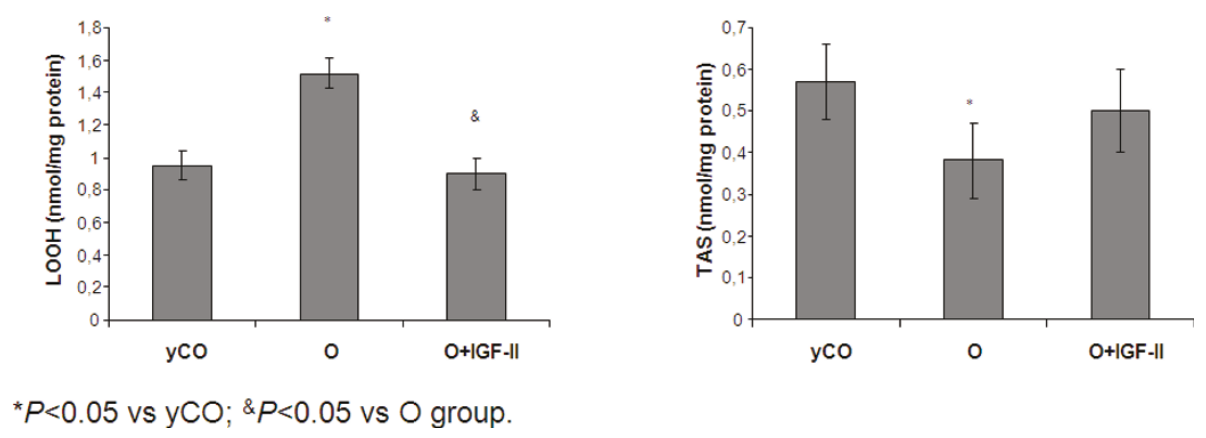

Figure 4 Lipid oxidative damage and Total Antioxidant Status (TAS) in isolated mitochondria from the three experimental groups.

Understanding that aging is mainly a condition of IGFs deficiency, more than $\mathrm{GH}$, we have recently reported that the exogenous administration of IGF-II induces similar effects of IGF-I in aging rats, without increasing testosterone levels [6]. Therefore, these data allow us to confirm that the neuroprotective and hepatoprotective actions are owed to specific properties of IGFs.

In this context, since mitochondria are one of the most important cellular targets of IGF-I, the present study analyzed the effects of IGF-II therapy on hepatic mitochondria from old animals.

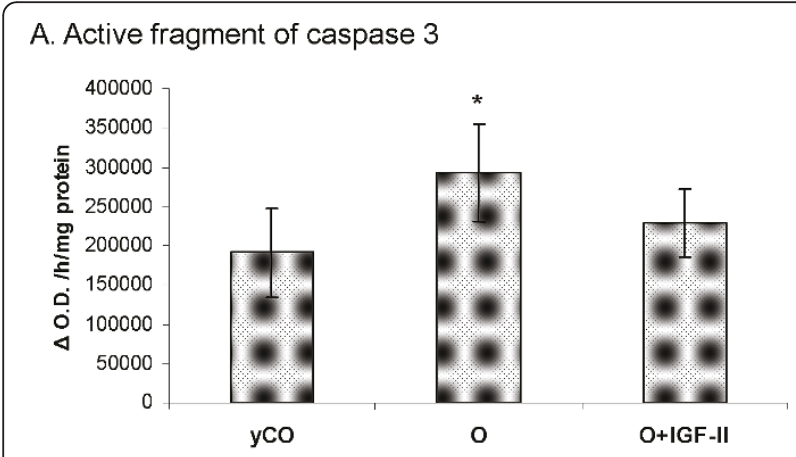

B. Caspase 9

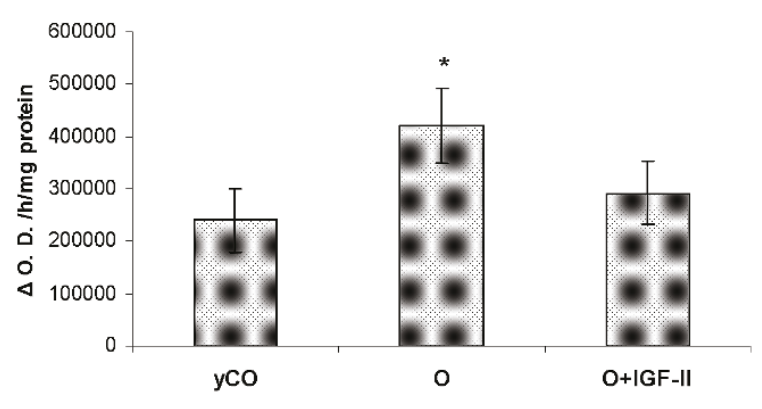

${ }^{*} P<0.05$ vs yCO

Figure 5 Assays for caspases 3 and 9 associated activity.
Results in this paper showed that mitochondrial dysfunction leading to apoptosis (by caspase activation) was normalized by IGF-II therapy, at low doses. In fact, IGFII treatment during 30 days recovered mitochondrial oxidative damage, mitochondrial proton gradient (resulting in an increase of MMP) and ATP synthesis and reduced free radical generation by mitochondria, proton leak rate and the vulnerability for pore opening in ANT which was associated to a reduction of caspase activation compared with untreated old rats.

We had previously characterized mitochondrial dysfunction in aging rats [5]. The observed reduction of MMP with an increased generation of $\mathrm{H}_{2} \mathrm{O}_{2}$ suggests that oxygen is wasted by damaged mitochondria producing ROS instead of a normal proton gradient that is the driving force of ATP synthase [14]. IGF-II therapy was able to reduce mitochondrial membrane damage and restore all parameters of mitochondrial function as IGF-I replacement therapy.

Together, these data suggest an extramitochondrial protection of mitochondria by IGFs, which is not fully established. Previously, we reported that low doses of IGF-I restored the expression of the serine protease inhibitor 2 ( $\alpha 1$ - antichymiotripsinogen) in cirrhotic rats [23], which could contribute to the outlined mitochondrial protection. In agreement with the results in this paper, it has been reported that IGF-I and II have antiapoptotic properties [24-27].

The main finding in this work was that IGF-II at low doses acts as an analogous of IGF-I inducing cell resistance to apoptosis by oxidative stress through mitochondrial protection leaded to ATP production. IGF-II therapy resulted -as IGF-I replacement therapy- in an increment of ATP synthesis. Interestingly, several beneficial effects of IGF-II in aging [6] could be related to an increased ATP availability similar to those described for IGF-I therapy $[4,5]$, in accordance with Sonntag WE et al [28]. This mechanism could explain, at least in part, a significant amount of evidence that have been accumulated during the last years indicating that IGF-I and 
IGF-II are potent neuronal mitogens and neurotrophic factors [29-35], and more recently the reported action of IGF-II administration in the enhancing memory retention and preventing forgetting [36], suggesting this hormone as a possible novel target for cognitive enhancement therapies.

Another point that deserves particular mention is that IGF-II treatment improved significantly lipid metabolism, diminishing cholesterol and triglycerides and increasing free fatty acids circulating levels [6]. Since fatty acids are synthesized at mitochondria, this result is consistent with both the mentioned normalization of mitochondrial function, and previously reported findings by Liang $\mathrm{G}$ and col. [32].

\section{Conclusion}

In conclusion, results in this paper reinforce seriously this concept: aging is mainly a condition of IGFs deficiency, in which mitochondrial dysfunction is one of the most relevant endpoint as an intracellular source of free radicals perpetuating oxidative cellular damage and causing ATP depletion. This work provides new evidence regarding the impact of IGFs declination in aging, clearly suggesting a strong clinical relevance since IGFII therapy reduces age-related side effects in rats without increasing testosterone levels, potentetially worsening diseases such as prostate hypertrophy or neoplasia.

\section{Additional material}

Additional file 1: Mitochondrial Membrane Potential (expressed as arbitrary units of fluorescence, AUF) and oxygen consumption in isolated liver mitochondria from the three experimental groups, using Glutamate/Malate as substrates.

\section{List of Abbreviations}

ANT: adenine nucleotide translocase; AUF: arbitrary units of fluorescence; bw: body weight; EC: Enzyme Commission of the International Union of Biochemistry; IGF: Insulin-Like Growth Factor; MDA: malondialdehyde; MMP: mitochondrial membrane potential; ns: not significant; O: untreated old rats; O+IGF-II: aging rats treated with IGF-II; PCC: protein carbonyl content; RH123: rhodamine 123 dye; ROS: reactive oxygen species; S: sensitivity; TAS: total antioxidant status; yCO: young controls.

\section{Acknowledgements}

This work has been supported by the Spanish I+D Program SAF-2009-08319. We thank Dr. Jesús Hernández Cabrero and Dr. José A Sacristán, Lilly Laboratories (Madrid, Spain), for providing research grants and the IGF-II used in this study.

We also specially thank to Dr. Jordi Muntané, Ms Yolanda Rico and Mr José M Garrido for their generous help.

\section{Author details}

'Department of Physiology, School of Medicine, University of Málaga, 29071 Málaga, Spain. ${ }^{2}$ Department of Medical Physiology, CEU-San Pablo University School of Medicine Institute of Applied Molecular Medicine (IMMA) Boadilla del Monte, 28668 Madrid, Spain.

\section{Authors' contributions}

MG-F, JEP and IS performed the research; LG analyzed the data; and IC-C designed the research, carried out the in vivo protocol and wrote the paper. All authors have read and approved the final manuscript.

\section{Competing interests}

The authors declare that they have no competing interests. These results have been registered as P200601523.

Received: 26 February 2011 Accepted: 28 July 2011

Published: 28 July 2011

\section{References}

1. Hoffman AR, Pyka G, Lieberman SA, Ceda GP, Marcus R: The sompatopause. Growth hormone and somatomedins during lifespan New York: Springer-Verlag; 1993, 265-274

2. Ceda GP, Dall'Aglio E, Maggio M, Lauretani F, Bandinelli S, Falzoi C, Grimaldi W, Ceresini G, Corradi F, Ferrucci L, Valenti G, Hoffman AR: Clinical implications of the reduced activity of the GH-IGF-I axis in older men. $J$ Endocrinol Invest 2005, 28:96-100.

3. Melling TR, Nylen ES: Growth hormone deficiency in adults: a review. Am J Med Sci 1996, 311:153-166.

4. García-Fernández M, Delgado G, Puche JE, González-Barón S, CastillaCortázar I: Low doses of insulin-like growth factor I improve insulin resistance, lipid metabolism, and oxidative damage in aging rats. Endocrinology 2008, 149(5):2433-2442.

5. Puche JE, García-Fernández M, Muntané J, Rioja J, González-Barón S, Castilla Cortazar I: Low doses of insulin-like growth factor-I induce mitochondrial protection in aging rats. Endocrinology 2008, 149(5):2620-2627.

6. Castilla-Cortázar I, García-Fernández M, Sierra I, Puche JE, Delgado G, Guerra L, González-Barón S: Hepatoprotection and neuroprotection induced by low doses of IGF-II in aging rats. Journal of Translational Medicine.

7. Kowaltowski AJ, Vercesi E: Mitochondrial damage induced by conditions of oxidative stress. Free Radic Biol Med 1999, 26:463-471.

8. Cardoso SM, Pereira C, Oliveira CR: Mitochondrial function is differentially affected upon oxidative stress. Free Radic Biol Med 1999, 26:3-13.

9. Bras M, Queenan B, Susin SA: Programmed cell death via mitochondria: different modes of dying. Biochemistry (Mosc) 2005, 70:231-239.

10. Earnshaw WC, Martins LM, Kaufmann SH: Mammalian caspases: structure, activation, substrates, and functions during apoptosis. Annu Rev Biochem 1999, 68:383-424.

11. Brand MD, Pakay JL, Ocloo A, Kokoszka J, Wallace DC, Brookes PS, Cornwall EJ: The basal proton conductance of mitochondria depends on adenine nucleotide translocase content. Biochem J 2005, 392(Pt 2):353-362.

12. O'Connor JE, Vargas JL, Kimler BF, Hernandez-Yago J, Grisolia S: Use of rhodamine 123 to investigate alterations in mitochondrial activity in isolated mouse liver mitochondria. Biochem Biophys Res Commun 1988 151:568-573.

13. Brand MD: The proton leak across the mitochondrial inner membrane. Biochim Biophys Acta 1990, 1018:128-133.

14. Brand MD: Measurement of mitochondrial proton motive force. $A$ practical approach Oxford University Press; 1995, 39-62.

15. Monemdjou S, Kozak LP, Harper ME: Mitochondrial proton leak in brown adipose tissue mitochondria of Ucp1-deficient mice is GDP insensitive. Am J Physiol 1999, 276(6 Pt 1):1073-1082.

16. Cortese JD, Voglino AL, Hackenbrock CR: Persistence of cytochrome c binding to membranes at physiological mitochondrial intermembrane space ionic strength. Biochim Biophys Acta 1994, 1228:216-228.

17. National Academy of Sciences: The guiding principles for research involving animals. Bethesda, MD: National Institutes of Health; 1991

18. Vieira HL, Haouzi D, El Hamel C, Jacotot E, Belzacq AS, Brenner C, Kroemer G: Permeabilization of the mitochondrial inner membrane during apoptosis: impact of the adenine nucleotide translocator. Cell Death Differ 2000, 7:1146-1154.

19. Halestrap AP, Woodfield KY, Connern CP: Oxidative stress, thiol reagents, and membrane potential modulate the mitochondrial permeability transition by affecting nucleotide binding to the adenine nucleotide translocase. J Biol Chem 1997, 272:3346-3354. 
20. Arab K, Steghens JP: Plasma lipid hydroperoxides measurement by an automated xylenol orange method. Anal Biochem 2004, 325:158-163.

21. Miller NJ, Rice-Evans C, Davies MJ: A new method for measuring antioxidant activity. Biochem Soc Trans 1993, 21:95S

22. Voss P, Siems W: Clinical oxidation parameters of aging. Free Radic Res 2006, 40:1339-1349.

23. Mirpuri E, Garcia-Trevijano ER, Castilla-Cortazar I, Berasain C, Quiroga J, Rodriguez-Ortigosa C, Mato JM, Prieto J, Avila MA: Altered liver gene expression in $\mathrm{CCl} 4$-cirrhotic rats is partially normalized by insulin-like growth factor-I. Int J Biochem Cell Biol 2002, 34:242-252.

24. Yamamura T, Otani H, Nakao Y, Hattori R, Osako M, Imamura H: IGF-I differentially regulates $\mathrm{BCl}-\mathrm{xL}$ and $\mathrm{Bax}$ and confers myocardial protection in the rat heart. Am J Physiol Heart Circ Physiol 2001, 280:1191-1200.

25. Tsujimoto Y: Cell death regulation by the Bcl-2 protein family in the mitochondria. J Cell Physiol 2003, 195:158-167.

26. Kondo T, Kitano T, Iwai K, Watanabe M, Taguchi Y, Yabu T, Umehara H, Domae N, Uchiyama T, Okazaki T: Control of ceramide-induced apoptosis by IGF-1: involvement of PI-3 kinase, caspase-3 and catalase. Cell Death Differ 2002, 9:682-692.

27. Ness JK, Scaduto RC, Wood TL: IGF-I prevents glutamate-mediated bax translocation and cytochrome $\mathrm{c}$ release in $\mathrm{O} 4+$ oligodendrocyte progenitors. Glia 2004, 46:183-94.

28. Sonntag WE, Bennett $C$, Ingram $R$, Donahue A, Ingraham J, Chen $H_{\text {, }}$ Moore T, Brunso-Bechtold JK, Riddle D: Growth hormone and IGF-I modulate local cerebral glucose utilization and ATP levels in a model of adult-onset growth hormone deficiency. Am J Physiol Endocrinol Metab 2006, 291(3):604-610

29. Trejo JL, Carro E, Lopez-Lopez C, Torres-Aleman I: Role of serum insulinlike growth factor I in mammalian brain aging. Growth Horm IGF Res 2004, 14(Suppl A):S39-43.

30. Tong $M$, Dong M, de la Monte SM: Brain insulin-like growth factor and neurotrophin resistance in Parkinson's disease and dementia with Lewy bodies: potential role of manganese neurotoxicity. J Alzheimers Dis 2009, 16(3):585-599.

31. Syroid DE, Zorick TS, Arbet-Engels C, Kilpatrick TJ, Eckhart W, Lemke G: A role for insulin-like growth factor-I in the regulation of Schwann cell survival. J Neurosci 1999, 19:2059-2068.

32. Liang G, Cline GW, Macica CM: IGF-1 stimulates de novo fatty acid biosynthesis by Schwann cells during myelination. Glia 2007, 55:632-641

33. Fernandez S, Fernandez AM, Lopez-Lopez C, Torres-Aleman I: Emerging roles of insulin-like growth factor-I in the adult brain. Growth Horm IGF Res 2007, 17(2):89-95.

34. Llorens-Martín M, Torres-Alemán I, Trejo JL: Mechanisms mediating brain plasticity: IGF1 and adult hippocampal neurogenesis. Neuroscientist 2009, 15(2):134-48

35. Sullivan KA, Kim B, Feldman EL: Insulin-like growth factors in the peripheral nervous system. Endocrinology 2008, 149(12):5963-71.

36. Chen DY, Stern SA, Garcia-Osta A, Saunier-Rebori B, Pollonini G, BambahMukku D, Blitzer RD, Alberini CM: A critical role for IGF-II in memory consolidation and enhancement. Nature 2011, 27:469(7331):491-7.

doi:10.1186/1479-5876-9-123

Cite this article as: Garcia-Fernandez et al: Liver mitochondrial dysfunction is reverted by insulin-like growth factor II (IGF-II) in aging rats. Journal of Translational Medicine 2011 9:123.

\section{Submit your next manuscript to BioMed Central and take full advantage of:}

- Convenient online submission

- Thorough peer review

- No space constraints or color figure charges

- Immediate publication on acceptance

- Inclusion in PubMed, CAS, Scopus and Google Scholar

- Research which is freely available for redistribution

Submit your manuscript at www.biomedcentral.com/submit
Biomed Central 